\title{
Conjugated bile acids in serum and secretions in response to cholecystokinin/secretin stimulation in children with cystic fibrosis
}

\author{
T A ROBB, G P DAVIDSON, AND C KIRUBAKARAN
}

From the Gastroenterology Unit, The Adelaide Children's Hospital, North Adelaide, South Australia, Australia, and the Gastroenterology Unit, Christian Medical College, Vellore, India

SUMMARY More than $80 \%$ of patients with cystic fibrosis have poor pancreatic function, and have large daily faecal bile acid losses. This has been postulated to lower luminal bile acid concentrations and adversely affect fat absorption. We studied, for the first time, quantitative individual conjugated duodenal bile acid secretion rates into the duodenum during cholecystokinin/secretin infusion in 55 cystic fibrosis patients and six controls, using a quantitative non-absorbable marker technique. We were able to show adequate duodenal total bile acid concentrations and normal secretion rates in these children. The bile acid secretion pattern in cystic fibrosis patients showed a marked increase in bile acid concentration during cholecysto$\mathrm{kinin} / \mathrm{secretin}$ infusion, to levels which were above the critical micellar concentration indicating that the gall bladder is a functional organ in this disease. The subsequent fall in secretion rate was similar to controls. We have documented a significantly raised glycine/taurine bile acid conjugation ratio in duodenal juice from cystic fibrosis patients and suggest that the combined effects of lowered ileal $\mathrm{pH}$ and increased glycine conjugated proportion of bile acids may cause precipitation of bile acids leading to decreased fat absorption and large faecal bile acid losses. To further investigate bile acid secretion in children with cystic fibrosis, we modified the high performance thin layer chromatography/densitometry method to enable measurement of individual glycine and taurine conjugates in serum. In comparing cystic fibrosis patients and controls, we were able to determine a group of $18(36 \%)$ with bile acid evidence of liver damage who also showed reduced bile acid secretion into the duodenum. We were unable to study changes in serum bile acids during cholecystokinin/secretin infusion because of the high level of bile acid contamination in Boots Secretin. Some patients showed raised fasting serum bile acid concentrations more than two years before changes in conventional liver function tests or clinically evident liver disease. We have shown fasting serum bile acids to be a sensitive measure of liver dysfunction in cystic fibrosis and postulate that raised proportions of glycine conjugated bile acids may be responsible for the high incidence of liver disease in cystic fibrosis.

More than $80 \%$ of children with cystic fibrosis have poor pancreatic function, ${ }^{1}$ causing significant nutrient malabsorption and having a deleterious effect on prognosis. ${ }^{2}$ Despite attempts to overcome the malabsorption by using pancreatic enzyme replacement daily with meals, most reports show that fat absorption is still not normal. ${ }^{45}$

Address for correspondence: Dr G P Davidson. Gastroenterology Unit, Adelaide Children's Hospital, King William Road. North Adelaide, South Australia, Australia 5006.

Received for publication 3 December 1984
Children with cystic fibrosis have been shown to excrete large amounts of bile acid in faeces ${ }^{6-8}$ and have raised glycine to taurine conjugation ratios. ${ }^{9-11}$ Some investigators have suggested that bile acid concentrations in cystic fibrosis are low or that the pool size is reduced, and this may be the reason for residual fat malabsorption. In view of these findings and suggestions, and because children with cystic fibrosis secrete small volumes of viscous bile, we decided to investigate the bile acid status of patients with cystic fibrosis by determining the individual 
conjugated bile acid concentrations, their secretion rates per kilogram per minute and relative conjugation with glycine and taurine during a standard pancreatic function test.

Absorption of bile acids after secretion into the gut in response to a meal or direct hormonal stimulation, takes place passively by non-ionic diffusion throughout the small bowel, but most reabsorption relies on the active transport mechanism in the terminal ileum. Because of the highly efficient extraction of circulating bile acids by the liver, blood levels are low in health with a postprandial rise which reflects temporary overloading of the extraction process. ${ }^{12}$

Liver disease is a well established component of cystic fibrosis but as yet, no satisfactory explanation has been proposed. ${ }^{11}$ Many authors believe serum bile acid concentrations to be a sensitive indication of liver status ${ }^{1314}$ but Ewerth ${ }^{12}$ has suggested that high fasting levels may be caused by more efficient passive uptake of glycine conjugated bile acids because of their higher $\mathrm{pKa}$. Raised levels can also occur in patients with bacterial overgrowth caused by excessive absorption of deconjugated bile acids. ${ }^{14}$ We decided that methods for determining serum bile acids should include quantitation of the individual glycine and taurine conjugates. In view of our previous experience with a high performance thin layer chromatography-densitometry technique for duodenal juice bile acids, ${ }^{15}$ we modified this method for serum analysis, and studied fasting serum bile acids in patients with cystic fibrosis.

\section{Methods}

\section{PATIENTS}

Non-cystic fibrosis control subjects (three male, three female) aged from 28 months to 167 months (mean 95 months), were investigated for suspected cystic fibrosis and/or pancreatic insufficiency. All gave normal test results for pancreatic parameters when compared with the data from Gaskin et al, ${ }^{16}$ and none had evidence of hepatobiliary disorders. The final diagnoses for these patients were: asthma (2), failure to thrive (2), ammotile cilia syndrome and chronic diarrhoea (2).

Sixty five cystic fibrosis patients (35 male, 30 female) aged from eight months to 278 months (mean 79 months) had pancreatic function tests. The diagnosis was based on duplicate sweat chloride concentrations of $>60 \mathrm{mmol} / \mathrm{l}$ in at least $100 \mathrm{mg}$ of sweat after pilocarpine iontophoresis. ${ }^{17}$ Fasting venous blood samples were obtained after an overnight fast from all six controls and 48 of the cystic fibrosis patients, eight of whom had some residual pancreatic function as determined by tryp- sin secretion rates above $0 \cdot 1$ units $/ \mathrm{kg} / \mathrm{min}$.

Faecal fat was determined on a 72 hour collection according to Van de Kamer et al ${ }^{18}$ while the patients were taking their normal enzyme supplements (cotazyme or viokase), and where necessary, antibiotics. Fat intake was quantitated and a coefficient of fat absorption calculated.

Individual conjugated bile acids in the duodenal juice obtained from a standardised pancreatic function test were quantitated by a high performance thin layer chromatography-densitometry methodology. ${ }^{15}$ Duodenal juice was spotted directly onto the plates, and so aqueous phase levels were not determined. Only 'total' concentrations were measured, and therefore include both aqueous and insoluble bile acids.

Pancreatic function tests were carried out using a standard protocol and continuous simultaneous intravenous cholecystokinin and secretin infusion, both at $0 \cdot 125 \mathrm{U} / \mathrm{kg} / \mathrm{min}$ for 90 minutes, after enzyme therapy had been withheld for at least 12 hours, essentially as described by Gaskin et al. ${ }^{16}$ Gastric secretions were separately and continuously aspirated and duodenal juice was collected on ice for 20 minutes before hormone infusion (basal) and for three 30 minute periods during stimulation. The non-absorbable marker bromosulphophthalein, ${ }^{19}$ was continuously infused into the proximal port of a double lumen tube which had a distal duodenal aspiration port at least $50 \mathrm{~mm}$ away at the ligament of Trietz. This allowed quantitation of secretion rates. Trypsin was determined titrimetrically by the method of Wiggins, ${ }^{20}$ and used to assess pancreatic function rather than lipase or amylase because of the lower individual variability for this parameter. All results are expressed as mean \pm SD and have been corrected for bromosulphophthalein recovery.

Conventional tests of liver function including aspartate transaminase, alanine transaminase, serum $\gamma$-glutamyl-transpeptidase, serum alkaline phosphatase, and bilirubin were done by routine laboratory methods.

Serum bile acids were measured by extracting $0.5-1.0 \mathrm{ml}$ of serum with reversed phase octadecylsilane bonded silica cartridges (Sep-Pak- $\mathrm{C}_{18}$ : Waters Associated Inc., Milford, USA) essentially as described by Setchell and Worthington ${ }^{21}$ but using $0.004 \mathrm{~mol} / \mathrm{l}$ sodium hydroxide as the diluent. Extracted bile acids were then eluted off with $4.0 \mathrm{ml}$ of methanol, taken to dryness at $90^{\circ} \mathrm{C}$ with an air stream, then reconstituted to $50 \mu \mathrm{l}$ with methanol. Samples and standards were treated identically. The subsequent separation of the individual glycine and taurine conjugates was done on silica gel plates modifying our previously published HPTLC technique. ${ }^{15}$ 
The solvent used for serum bile acid separation was similar to that described by O'Moore and Percy-Robb, ${ }^{22}$ chloroform: methanol:glacial acetic acid:water - 18:6.6:2:1.8 v/v. Ten microlitres of samples and standards (or dilutions thereof) were applied as $4.0 \mathrm{~mm}$ streaks and chromatography performed in an unsaturated Camag linear developing chamber (sandwich configuration) for one hour. After drying in an air stream, the bile acids were detected by dipping the plate in a solution of $2 \% \mathrm{w} / \mathrm{v}$ phosphomolybdic acid containing $5 \% \mathrm{v} / \mathrm{v}$ concentrated sulphuric acid, followed by air drying and heating at $100-110^{\circ} \mathrm{C}$ for several minutes. Quantitation was achieved by densitometry, and reference to the areas from standards. This allowed taurocholate and glycocholate to be determined, the sum of taurochenodeoxycholate/taurodeoxycholate and the sum of glycochenodeoxycholate/glycodeoxycholate to be quantitated.

Sensitivity was determined by establishing the minimum concentration necessary to produce a signal at least $\times 2$ background densitometry noise. Accuracy was determined by the recovery of added standards at two concentrations to pooled serum samples. Precision was determined by multiple analysis of pooled serum samples containing bile acids.

The statistical significance of differences between means was calculated using Student's $t$ test, where $p$ values $<0.05$ were regarded as significant. Linear regression analysis was used to determine the correlation between variables.

\section{Results}

GENERAL

Test results where the bromosulphophthalein recovery was $<20 \%$ (four male, six female cystic fibrosis patients), were discarded. Trypsin secretion rates, bromosulphophthalein recoveries, ages, weights and faecal fat estimations are shown in Table 1.

Linear regression analysis of weight $v s$ age showed highly significant correlations for both cystic fibrosis and controls $(r>0.92)$, as expected. The cystic fibrosis weight increase with age followed the 25th percentile line of Jones and Hemphill ${ }^{23}$ until about puberty. Less than $7 \%$ of cystic fibrosis patients were $<3$ rd percentile for weight in this age group whereas four of 11 patients $(36 \%)$ after the age of puberty were $<3$ rd percentile.

The cystic fibrosis patients were divided into three subgroups based on their pancreatic function as determined by trypsin secretion rates during cholecystokinin/secretin stimulation. The majority had poor pancreatic function $(n=45$; trypsin $<0.01$ $\mathrm{U} / \mathrm{kg} / \mathrm{min}$ ) but about $18 \%$ had some residual function $(\mathrm{n}=5$; trypsin $0 \cdot 01-1.0 \mathrm{U} / \mathrm{kg} / \mathrm{min}: \mathrm{n}=5$; trypsin $>1.0 \mathrm{U} / \mathrm{kg} / \mathrm{min})$. The five cystic fibrosis patients with near normal pancreatic function were significantly younger (mean 40 months) than those with poor pancreatic function (mean 84 months).

Coefficients of fat absorption in cystic fibrosis patients with poor pancreatic function (mean $68.5 \%$ ) were significantly lower than controls (mean $95.7 \%$ ). Even cystic fibrosis children with near normal trypsin secretion rates had significantly poorer fat absorption (mean $85 \cdot 3 \%$ ).

\section{CONJUGATED DUODENAL JUICE BILE ACIDS Quantitative results}

Duodenal juice bile acid concentrations and secretion rates are shown in Table 2. In cystic fibrosis patients and controls, the levels of conjugated bile acid in the lumen were above the critical micellar concentration ${ }^{24}$ during cholecystokinin/secretin infusion. In cystic fibrosis, total bile acid secretion

Table 1 Mean values and standard deviations for general parameters from cystic fibrosis patients and controls

\begin{tabular}{|c|c|c|c|c|c|}
\hline & \multicolumn{3}{|c|}{ Cystic fibrosis (trypsin (U/kg/min)) } & \multirow[t]{2}{*}{$\begin{array}{l}\text { Non-cystic } \\
\text { fibrosis } \\
\text { control }\end{array}$} & \multirow[t]{2}{*}{$\begin{array}{l}\text { All cystic } \\
\text { fibrosis } \\
\text { patients }\end{array}$} \\
\hline & $\begin{array}{l}<0 \cdot 1 \\
(45)\end{array}$ & $0 \cdot 1-1 \cdot 0$ & $>1 \cdot 0$ & & \\
\hline \multirow[t]{2}{*}{ Trypsin (U/kg/min) } & $0.006^{*}$ & $0 \cdot 26^{*}$ & $6 \cdot 05$ & $4 \cdot 3$ & $0.58^{*}$ \\
\hline & 0.014 & $0 \cdot 25$ & $5 \cdot 67$ & 1.9 & $2 \cdot 33$ \\
\hline \multirow[t]{2}{*}{ BSP recovery \% } & $55 \cdot 8$ & $49 \cdot 4$ & $34 \cdot 1$ & $47 \cdot 6$ & $53 \cdot 2$ \\
\hline & $20 \cdot 4$ & $19 \cdot 8$ & $13 \cdot 2$ & $26 \cdot 6$ & $20 \cdot 6$ \\
\hline \multirow[t]{2}{*}{ Age (months) } & $83 \cdot 6$ & $56 \cdot 8$ & $40 \cdot 0^{*}$ & 95.4 & $77 \cdot 2$ \\
\hline & $69 \cdot 5$ & 88.5 & $25 \cdot 5$ & $50 \cdot 5$ & $69 \cdot 0$ \\
\hline \multirow[t]{2}{*}{ Weight (kg) } & 21.9 & $20 \cdot 0$ & $15 \cdot 1$ & $22 \cdot 2$ & $21 \cdot 2$ \\
\hline & $13 \cdot 3$ & $20 \cdot 0$ & $5 \cdot 6$ & $12 \cdot 8$ & $13 \cdot 4$ \\
\hline \multirow[t]{2}{*}{ Coefficient of fat absorption } & $68 \cdot 5^{*}$ & $89 \cdot 7^{*}$ & $85 \cdot 3^{*}$ & $95 \cdot 7$ & $71 \cdot 6^{*}$ \\
\hline & 19.4 & $6 \cdot 8$ & $9 \cdot 7$ & $0 \cdot 7$ & $19 \cdot 3$ \\
\hline
\end{tabular}

* Significant difference from non-cystic fibrosis controls. 
Table 2 Mean values and standard deviations for quantitative duodenal juice conjugated bile acid data

\begin{tabular}{|c|c|c|c|c|c|}
\hline & \multicolumn{3}{|c|}{ Cystic fibrosis (trypsin $(U / \mathrm{kg} / \mathrm{min}))$} & \multirow{2}{*}{$\begin{array}{l}\text { Non-cystic } \\
\text { fibrosis } \\
\text { control }\end{array}$} & \multirow{2}{*}{$\begin{array}{l}\begin{array}{l}\text { All cystic } \\
\text { fibrosis } \\
\text { patients }\end{array} \\
\\
(55)\end{array}$} \\
\hline No & $\begin{array}{l}<0 \cdot 1 \\
(45)\end{array}$ & $\begin{array}{l}0 \cdot 1-1 \cdot 0 \\
(5)\end{array}$ & $\begin{array}{l}>1 \cdot 0 \\
(5)\end{array}$ & & \\
\hline \multicolumn{6}{|l|}{ Total bile acid concentration } \\
\hline \multirow[t]{2}{*}{ Fasting (mmol/l) } & $9 \cdot 3^{*}$ & $9 \cdot 5^{*}$ & $4 \cdot 8^{*}$ & $1 \cdot 3$ & $8.9^{*}$ \\
\hline & $8 \cdot 4$ & $5 \cdot 6$ & $3 \cdot 0$ & $2 \cdot 0$ & 7.9 \\
\hline \multirow[t]{2}{*}{ Stimulation $(\mathrm{mmol} / \mathrm{l})$} & $14 \cdot 8^{*}$ & $9 \cdot 8$ & $6 \cdot 7$ & $5 \cdot 2$ & $13 \cdot 7^{*}$ \\
\hline & $9 \cdot 2$ & $5 \cdot 8$ & $5 \cdot 1$ & $2 \cdot 9$ & $8 \cdot 9$ \\
\hline \multicolumn{6}{|l|}{ Total bile acid secretion } \\
\hline \multirow[t]{2}{*}{ Rate: fasting $(\mu \mathrm{mol} / \mathrm{kg} / \mathrm{min})$} & $1 \cdot 17^{*}$ & $2 \cdot 62^{*}$ & $1 \cdot 72^{*}$ & $0 \cdot 42$ & $1 \cdot 35^{*}$ \\
\hline & $1 \cdot 30$ & $2 \cdot 46$ & 1.26 & 0.65 & 1.46 \\
\hline \multicolumn{6}{|l|}{ Glycine bile acid secretion } \\
\hline \multirow[t]{2}{*}{ Rate: fasting $(\mu \mathrm{mol} / \mathrm{kg} / \mathrm{min})$} & $0.94^{*}$ & $2 \cdot 00^{*}$ & $1 \cdot 16^{*}$ & $0 \cdot 27$ & $1 \cdot 05^{*}$ \\
\hline & 1.09 & 1.93 & $0 \cdot 87$ & $0 \cdot 43$ & $1 \cdot 18$ \\
\hline \multicolumn{6}{|l|}{ Taurine bile acid secretion } \\
\hline \multirow[t]{2}{*}{ Rate: fasting $(\mu \mathrm{mol} / \mathrm{kg} / \mathrm{min})$} & $0 \cdot 20$ & 0.62 & 0.56 & $0 \cdot 15$ & $0 \cdot 27$ \\
\hline & $0 \cdot 25$ & $0 \cdot 57$ & $0 \cdot 40$ & $0 \cdot 23$ & 0.33 \\
\hline \multicolumn{6}{|l|}{ Total bile acid secretion } \\
\hline \multirow[t]{2}{*}{ Rate: stimulation $(\mu \mathrm{mol} / \mathrm{kg} / \mathrm{min})$} & 1.97 & $1 \cdot 39$ & $1 \cdot 74$ & $2 \cdot 10$ & 1.90 \\
\hline & $1 \cdot 51$ & 0.40 & $1 \cdot 16$ & 1.46 & $1 \cdot 41$ \\
\hline \multicolumn{6}{|l|}{ Maximum total bile acid secretion } \\
\hline \multirow[t]{2}{*}{ Rate: stimulation $(\mu \mathrm{mol} / \mathrm{kg} / \mathrm{min})$} & $2 \cdot 78$ & 1.94 & $2 \cdot 37$ & $2 \cdot 59$ & $2 \cdot 67$ \\
\hline & 2.98 & $0 \cdot 80$ & 1.83 & $3 \cdot 15$ & $2 \cdot 77$ \\
\hline \multicolumn{6}{|l|}{ Glycine bile acid secretion } \\
\hline \multirow[t]{2}{*}{ Rate: stimulation $(\mu \mathrm{mol} / \mathrm{kg} / \mathrm{min})$} & $1 \cdot 58^{*}$ & 1.06 & 1.07 & 0.98 & 1.49 \\
\hline & $1 \cdot 23$ & $0 \cdot 33$ & 0.54 & 0.71 & $1 \cdot 14$ \\
\hline \multicolumn{6}{|l|}{ Taurine bile acid secretion } \\
\hline \multirow[t]{2}{*}{ Rate: stimulation $(\mu \mathrm{mol} / \mathrm{kg} / \mathrm{min})$} & $0 \cdot 39$ & $0 \cdot 33$ & 0.67 & 0.73 & $0 \cdot 40$ \\
\hline & $0 \cdot 39$ & $0 \cdot 11$ & 0.64 & $0 \cdot 54$ & $0 \cdot 40$ \\
\hline
\end{tabular}

* Significant difference from non-cystic fibrosis controls.

rates during the fasting period were significantly greater than controls, caused by an increase in glycine but not taurine conjugate secretions. The average conjugated bile acid secretion rate for cystic fibrosis patients during hormone infusion (mean $1.90 \mu \mathrm{mol} / \mathrm{kg} / \mathrm{min}$ ) was similar to controls (mean $2 \cdot 10 \mu \mathrm{mol} / \mathrm{kg} / \mathrm{min}$ ) and the maximum secretion rate for any stimulation period was similar for cystic fibrosis patients and the normal group.

In general, cystic fibrosis patients responded to cholecystokinin/secretin in a manner similar to the non-cystic fibrosis controls (Fig. 1). The mean secretion rates from each 30 minute post-stimulation period were similar for both groups and showed a similar fall-off in secretion with time. Eighteen cystic fibrosis patients with raised fasting serum bile acids had significantly lower bile acid secretion responses to cholecystokinin/secretin at all poststimulation periods, but still maintained duodenal bile acid concentrations above the CMC (mean 11.7 $\mathrm{mmol} / \mathrm{l})$.

\section{Qualitative results}

The glycine/taurine ratios and proportion of cholic acid are shown in Table 3 . The bile acid composition of the duodenal juice from cystic fibrosis patients was significantly different from controls. In cystic fibrosis patients, the glycine/taurine ratios and relative cholic acid concentrations were raised both in the fasting and stimulation periods. This alteration in glycine/taurine ratio became progressively more pronounced as pancreatic function worsened, but did not correlate with age. Using linear regres-

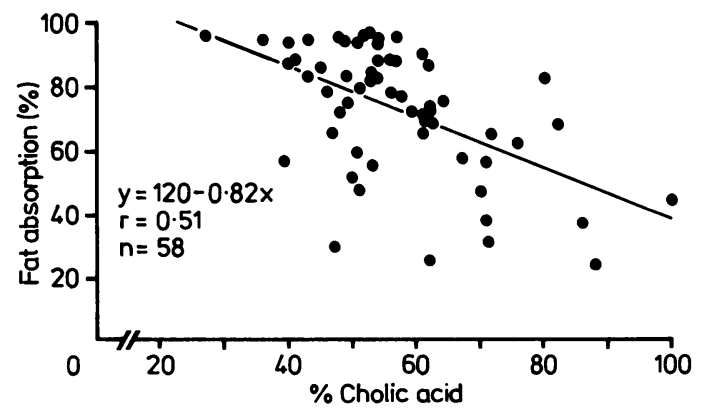

Fig. 1 Fat absorption versus percentage cholic acid in duodenal juice. Cystic fibrosis patients plus controls. 
Table 3 Mean values and standard deviations for qualitative duodenal juice conjugated bile acid data

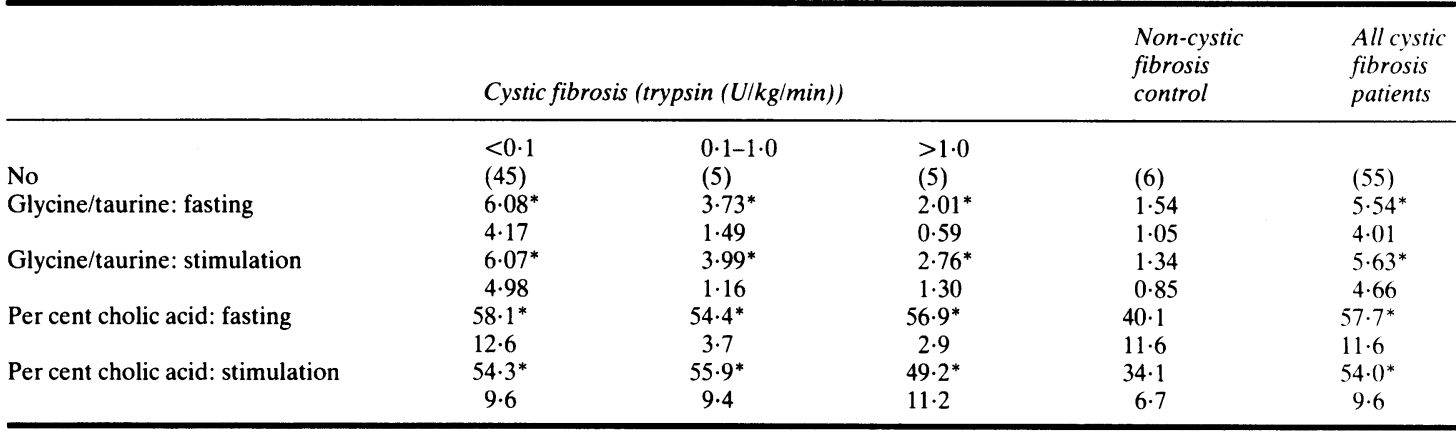

* Significant difference from non-cystic fibrosis controls.

sion analysis, the proportion of cholic acid in fasting duodenal juice was significantly correlated with fat absorption $(\mathrm{p}<0.001)$ in a negative but loose manner $(r=0.51)$ (Fig. 2). The fasting duodenal juice glycine/taurine ratio was similarly negatively correlated with fat absorption $(\mathrm{p}<0.001)$ but again was loose $(r=0.52)$ (Fig. 3). The proportion of cholic acid did not correlate with glycine/taurine ratio $(r=0.01)$ and the altered bile acid composition did not correlate with trypsin secretion rate.

\section{SERUM BILE ACIDS}

\section{Technique}

A densitometric scan showing standards and bile acids from extracted serum is shown in Figure 4. The separation of bile acids was clear cut but the

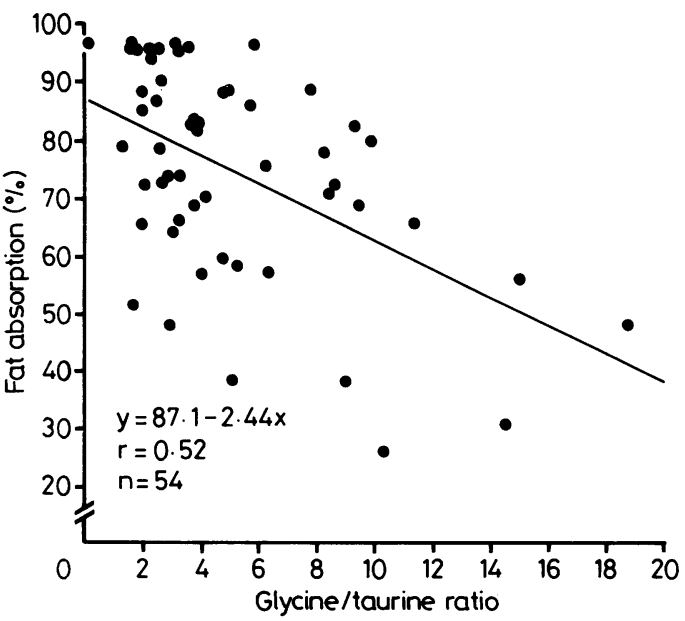

Fig. 2 Fat absorption versus glycine/taurine bile acid conjugation ratio in duodenal juice. Cystic fibrosis patients plus controls. conjugated isomer pairs chenodeoxycholic and deoxycholic acid were not resolved. Glycine and taurine conjugates were easily quantitated in this HPTLC system.

The lowest concentration quantitated using $1.0 \mathrm{ml}$ serum and spotting $10 \mu \mathrm{l}$ was $0.4 \mu \mathrm{mol} / \mathrm{l}$ which is equivalent to $0.02 \mu \mathrm{g}$ 'on plate'. Lower detection

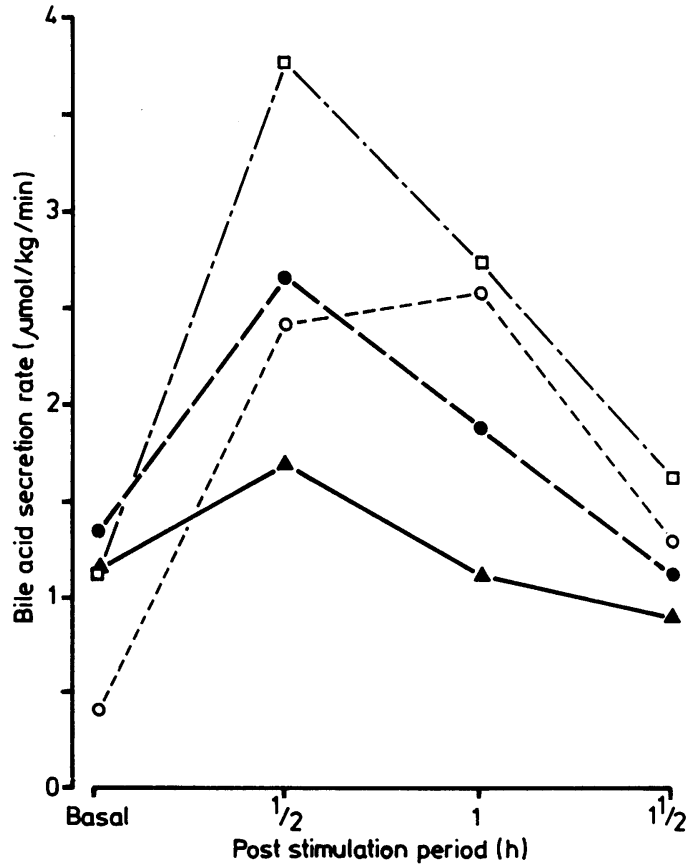

Fig. 3 Total conjugated bile acid secretion rates before and during cholecystokinin/secretin stimulation. $\bigcirc$ Control $(n=6)$. All cystic fibrosis patients $(n=54)$. $\square$ Cystic fibrosis - no liver disease $(n=36)$. $\Delta$ Cystic fibrosis - liver disease $(n=18)$. 


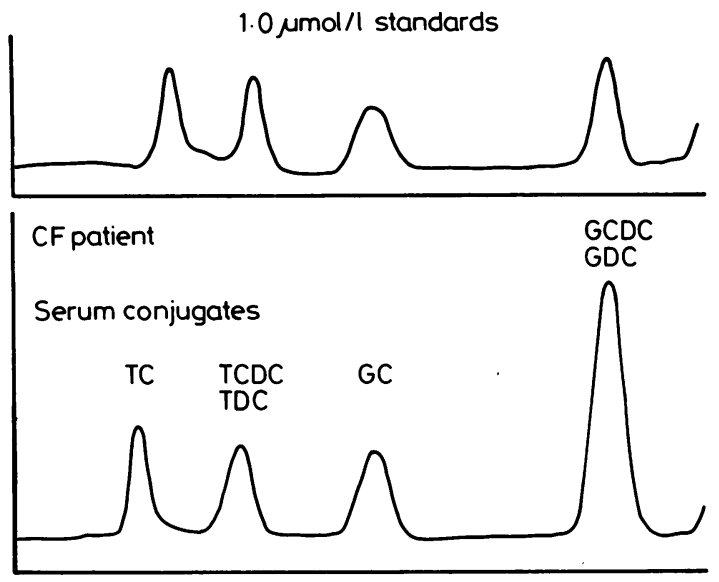

Fig. 4 Densitometer scan of standards and bile acids from extracted serum.

limits could be achieved by extracting larger serum samples and/or spotting larger volumes. The results were linear in the range $0.4-5.0 \mu \mathrm{mol} / \mathrm{l}$.

Analysis of duplicate serum samples spiked with $1.0 \mu \mathrm{mol} / \mathrm{l}$ or $2.0 \mu \mathrm{mol} / \mathrm{l}$ of the individual conjugated bile acids (eight replicates for each level) gave recoveries from $95 \%$ to $99 \%$ (average $97 \%$ ) for the higher levels, and from $96 \%$ to $102 \%$ (average $99 \%$ ) for low level additions. Ten aliquots of a serum pool to which $1.0 \mu \mathrm{mol} / \mathrm{l}$ of each standard was added, were analysed for conjugated bile acids and coefficients of variation ranged from $1.5 \%$ to $4.6 \%$ (average $2 \cdot 8 \%$ ).

\section{Fasting levels}

Total fasting bile acids and the individual glycine and taurine conjugate levels for cystic fibrosis patients and controls are shown in Table 4, and were obtained before the results of conventional liver function tests or pancreatic function tests were available.

Eighteen of the 48 cystic fibrosis patients (38\%) had total fasting serum bile acid concentrations above the literature normal range of $0-7 \mu \mathrm{mol} / 1^{14}$ and above the range of our controls $(0-6 \cdot 2 \mu \mathrm{mol} / \mathrm{l})$. These patients were statistically significantly older than other cystic fibrosis patients within the same pancreatic function group. The mean bile acid secretion rate into the duodenum in these patients, was significantly less in each of the cholecystokinin/ secretin stimulation periods (Fig. 5). There were no cystic fibrosis patients with residual pancreatic function who had raised fasting bile acids.

The rises in fasting bile acid concentration were caused by changes to both glycine and taurine conjugates.

As with fasting duodenal juice, the glycine/taurine

Table 4 Mean values and standard deviations for quantitative serum bile acid data

\begin{tabular}{|c|c|c|c|c|c|c|c|}
\hline & \multicolumn{5}{|c|}{ Cystic fibrosis (trypsin (U/ $\mathrm{kg} / \mathrm{min}))$} & \multirow[t]{2}{*}{$\begin{array}{l}\text { Non-cystic } \\
\text { fibrosis } \\
\text { control }\end{array}$} & $\begin{array}{l}\text { All cystic } \\
\text { fibrosis } \\
\text { patients }\end{array}$ \\
\hline & \multirow{2}{*}{\multicolumn{3}{|c|}{$\begin{array}{l}\dagger<0 \cdot 1 \\
\text { Bile acid concentration }(\mu \mathrm{mol} / \mathrm{l})\end{array}$}} & $0 \cdot 1-1 \cdot 0$ & $>1.0$ & & \\
\hline & & & & & & & \\
\hline & $<8$ & $>8$ & All & & & & \\
\hline & (22) & (18) & $(40)$ & (4) & (4) & (6) & (48) \\
\hline \multirow[t]{2}{*}{ Total concentration } & 4.5 & $28 \cdot 1^{*}$ & $15 \cdot 1^{*}$ & 2.9 & 4.9 & $4 \cdot 0$ & $13 \cdot 2^{*}$ \\
\hline & $2 \cdot 1$ & $34 \cdot 5$ & $25 \cdot 8$ & $1 \cdot 7$ & $1 \cdot 5$ & $2 \cdot 5$ & 23.9 \\
\hline No & (22) & (18) & (40) & (4) & (4) & (6) & (48) \\
\hline \multirow[t]{2}{*}{ Glycine concentration } & $3 \cdot 2$ & $18 \cdot 8^{*}$ & $10 \cdot 2^{*}$ & $2 \cdot 5$ & 3.0 & $2 \cdot 2$ & $9 \cdot 0^{*}$ \\
\hline & 1.9 & $19 \cdot 8^{*}$ & $15 \cdot 3$ & $2 \cdot 2$ & 0.9 & $1 \cdot 9$ & $14 \cdot 3$ \\
\hline No & $(22)$ & (18) & $(40)$ & (4) & (4) & (6) & (48) \\
\hline \multirow[t]{2}{*}{ Taurine concentration } & $1 \cdot 3$ & $4 \cdot 1^{*}$ & $2 \cdot 5$ & 0.4 & 1.8 & $1 \cdot 8$ & $2 \cdot 3$ \\
\hline & $1 \cdot 2$ & $4 \cdot 5$ & $3 \cdot 4$ & 0.5 & 0.8 & 0.9 & $3 \cdot 1$ \\
\hline No & (19) & (18) & (37) & (1) & (4) & (4) & (42) \\
\hline Glycine/taurine & 3.9 & 5.9 & $5 \cdot 0$ & & $1 \cdot 0$ & 0.6 & $4 \cdot 8$ \\
\hline No & (20) & (18) & (38) & (4) & (4) & (5) & (46) \\
\hline \multirow[t]{2}{*}{ Per cent cholic acid } & $37 \cdot 4$ & $31 \cdot 6$ & $34 \cdot 7$ & 28.0 & 35.6 & 23.5 & $34 \cdot 2$ \\
\hline & $15 \cdot 8$ & $11 \cdot 4$ & $14 \cdot 0$ & $5 \cdot 7$ & $24 \cdot 2$ & $12 \cdot 6$ & $14 \cdot 4$ \\
\hline No & $(22)$ & (18) & $(40)$ & (4) & (4) & (6) & $(48)$ \\
\hline \multirow[t]{2}{*}{ Age (months) } & $59 \cdot 0$ & $110 \cdot 3^{*}$ & $82 \cdot 1$ & $17 \cdot 3$ & 39 & 95 & 73 \\
\hline & $43 \cdot 8$ & $75 \cdot 7$ & $64 \cdot 8$ & $2 \cdot 0$ & 29 & 51 & 63 \\
\hline
\end{tabular}

* Significant difference from non-cystic fibrosis controls.

+ Cystic fibrosis patients with trypsin secretion rates less than $0 \cdot 1 \mathrm{U} / \mathrm{kg} / \mathrm{min}$ were subdivided according to bile acid concentration ( $<8 \mu \mathrm{mol} / \mathrm{l}=\mathrm{normal},>8 \mu \mathrm{mol} / /=$ abnormal $)$. 


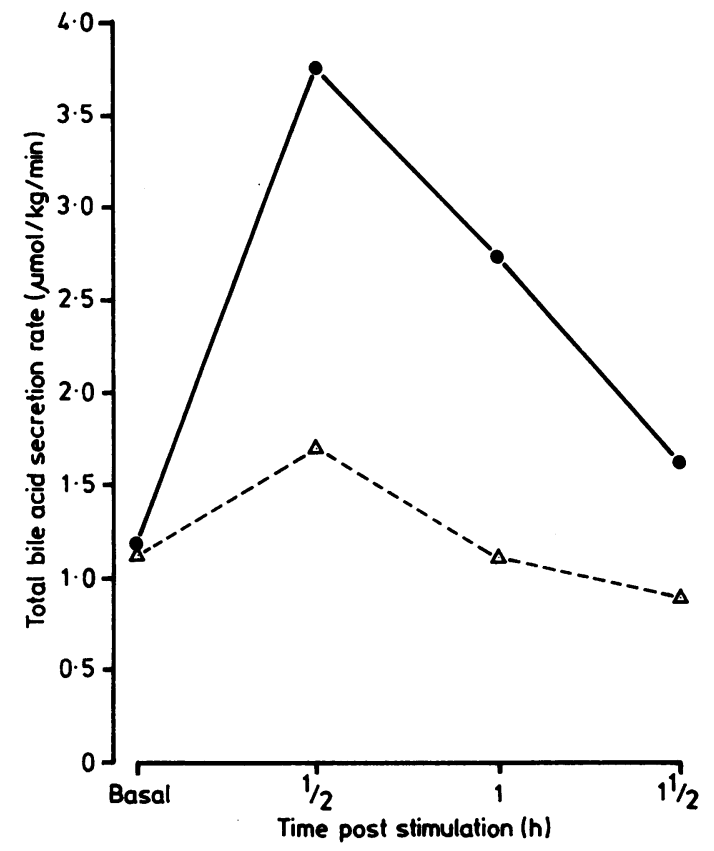

Fig. 5 Mean cholecystokinin/secretin total bile acid secretion rates into the duodenum in cystic fibrosis patients with trypsin secretion rates $<0.1$ units $/ \mathrm{kg} / \mathrm{min}$. Cystic fibrosis patients with normal fasting serum bile acids $(n=22)$. $\triangle$ Cystic fibrosis patients with raised fasting serum bile acids $(n=18)$.

ratio in serum from cystic fibrosis patients with poor pancreatic function was significantly raised compared with controls $(4.6 v s 1.6)$ but did not correlate with the fasting duodenal juice glycine/taurine ratio $(r=0 \cdot 15)$. The serum level of cholic acid conjugates relative to the total bile acid concentration was similar for all groups, and did not show the same altered pattern seen in cystic fibrosis duodenal juice.

\section{Levels during cholecystokinin/secretin infusion} Although blood samples were taken at $0 \cdot 5,1 \cdot 0,1 \cdot 5$ hours after hormonal intravenous stimulation, in the cystic fibrosis patients and controls, the bile acid results cannot be interpreted because of the massive contamination of secretin (Boots Co Ltd, Nottingham, England) by bile acids (R Butler, N Gehling personal communication). We examined the secretin preparation after reconstitution of 1 ampoule (90 Crick-Harper-Raper units) into $5 \mathrm{ml}$ of normal saline and found the total conjugated bile acid concentration to be $22.04 \mathrm{mmol} / \mathrm{l}$. The preparation, derived from pigs, also contained an unidentified bile acid with an Rf between glycocholate and glycodeoxycholate which is thought to be hyocholate, hyodeoxycholate or a conjugate of these ( $R$ Illman - personal communication). Blood samples, even from the control group, contained this extra contaminating bile acid after secretin infusion, and the total bile acid concentrations were of the order of 10 times higher than normally reported. ${ }^{25} 26$

\section{Other indices of liver disease}

Thirteen patients with raised fasting serum bile acids, also had other conventional liver function tests carried out as part of their routine screening. Seven of these showed clinical hepatomegaly whereas six had nothing to find. Six had raised parameters by conventional liver function testing, but seven were normal (Table 5). Three patients with raised fasting bile acids, clinically normal and with other normal liver function test results, showed rises to conventional liver function test results two to four years later, but were still clinically normal.

\section{Discussion}

\section{SERUM BILE ACID METHODOLOGY}

The precision, linearity, sensitivity and accuracy results indicate that adaption of the duodenal juice conjugated bile acid methodology ${ }^{15}$ was successful. The simplicity of the technique and batch processing enables $10-15$ serum samples to be processed daily and is suitable for routine use.

\section{DUODENAL JUICE BILE ACIDS}

Many have showed increased faecal bile acid losses in children with cystic fibrosis ${ }^{491027}$ and have postulated that the concentration of conjugated bile acids may be low and therefore suboptimal for lipolysis. Our data clearly show that the total

Table 5 Fasting serum bile acids and conventional liver function tests

Conventional liver function tests


concentrations of conjugated bile acids in cystic fibrosis were maintained above the accepted $\mathrm{CMC}^{24}$ and that secretion rates into the gut after hormonal (cholecystokinin/secretin) stimulation, were comparable to controls. This indicates that the reserve capacity of the liver to compensate for increased faecal losses was not exceeded in these cystic fibrosis patients. Even those patients with poor pancreatic function and fasting serum bile acid evidence of liver disease, still secreted bile acids into the duodenum at a rate which, although lower than other cystic fibrosis patients, still maintained levels above the CMC. The lower bile acid secretion rates in these older patients supports the hypothesis of Goodchild et al, ${ }^{11}$ that reduced faecal bile acid excretion from older cystic fibrosis patients may be related to reduced bile acid secretion due to liver disease.

The shape of the stimulation secretion rate curves for all cystic fibrosis groups was similar to controls, indicating that the gall bladder is a functional organ in cystic fibrosis, despite the ultrasound changes. ${ }^{28}$ The observation that fasting duodenal bile acid secretion rates in all cystic fibrosis groups were significantly greater than normal, agrees with the raised fasting bile acid concentrations shown by Goodchild et $_{\text {al }}{ }^{11}$ and indicates some impairment of gall bladder function. This means that bile acids in cystic fibrosis are continually circulating at a higher than normal rate, which may be part of the mechanism causing increased faecal losses in cystic fibrosis, as less than $100 \%$ of secreted bile acids are returned to the enterohepatic circulation each cycle.

Despite the normal quantitative secretion of bile acids in cystic fibrosis there were obvious qualitative differences from controls. Our finding of raised glycine/taurine ratios even in patients on enzyme replacement therapy, or with near normal pancreatic function, has previously been mentioned by others. $^{9-11}$ There was a gradation from mild to grossly raised values with decreasing pancreatic function, and the glycine/taurine was often in the range seen in patients with ileal disorders. ${ }^{29}$ Several factors may alter glycine/taurine patterns in cystic fibrosis including dietary taurine availability ${ }^{30}$ or absorption, ${ }^{10} 31$ different terminal ileal transport rates for taurine $v s$ glycine conjugates,${ }^{32}$ and excessive faecal bile acid losses necessitating increased liver synthesis and conjugation with resultant taurine depletion. ${ }^{29}$ It is also possible that the lowered ideal $\mathrm{pH}$ values in cystic fibrosis ${ }^{33} 34$ favour reabsorption of glycine conjugates due to their higher $\mathrm{pKa}$, allowing additional passive non-ionic diffusion along the entire small bowel for glycine but not taurine conjugates. ${ }^{35}$ Although Goodchild et $a l^{11}$ found duodenal $\mathrm{pH}$ values above 6.5 as we did, it must be remembered that both studies continuously and separately aspirated gastric contents during the duodenal collection periods.

Allowing for the many variables that might be expected to affect fat absorption in cystic fibrosis; including doses of enzyme capsules and compliance, the finding of a significant association between fat absorption and the glycine/taurine ratio is important. Whatever the cause for an altered glycine/ taurine ratio, such a change might be reasonably expected to alter fat absorption in cystic fibrosis because of the combination of lowered duodenal and ileal $\mathrm{pH}^{33}$ and increased precipitation $\mathrm{pH}$ in a mixture of bile acids containing a raised glycine conjugates component. ${ }^{36}$ The suggestion that taurine but not glycine conjugated bile acid stimulates lipolysis directly ${ }^{37}$ may also be a factor in reduced fat absorption in cystic fibrosis. The precipitation of glycine conjugated bile acids by calcium ${ }^{38}$ may be especially important in cystic fibrosis where the majority of bile acids are conjugated with glycine and so may be in an insoluble form.

Our finding of an increased proportion of cholic acid, is consistent with the view that this reflects increased bile acid malabsorption or decreased secondary (bacterial) bile acid formation because of regular antibiotic usage in cystic fibrosis. ${ }^{27}$ The latter mechanism appears most likely in those patients with near normal pancreatic function. The large faecal bile acid losses in cystic fibrosis may be partly caused by reduced ileal uptake ${ }^{39}$ and by increased bile acid precipitation resulting from low $\mathrm{pH}$ and relatively increased glycine conjugation. The fact that alterations to the glycine/taurine ratio appear unrelated to the changes in relative cholic acid concentration suggests that these qualitative changes in bile acid are influenced by separate factors.

Finally, despite having shown adequate conjugated bile acid concentrations and normal secretion rates in cystic fibrosis, the availability of the bile acids was not determined. Unfortunately we did not study the bile acid concentrations in the aqueous phase, but measured only total levels. Because the majority of bile acids in cystic fibrosis are conjugated with glycine, the low ileal $\mathrm{pH}$ may cause most of the bile acids to be precipitated. The reduced postprandial serum increase seen by Boyle et $a l^{40}$ is most probably the result of intestinal malabsorption of bile acids in cystic fibrosis. The qualitative changes in bile acids that we have shown are consistent with current knowledge and may merely reflect the increased bile acid malabsorption in cystic fibrosis patients on their antibiotic therapy. It is possible, however, that alterations to the bile acid composition, in association with abnormal ileal $\mathrm{pH}$ 
values in cystic fibrosis may directly affect fat absorption, so that correction of both abnormalities may be necessary before an improvement in fat absorption is achieved.

We are pursuing the bile acid aspect of fat absorption in cystic fibrosis by attempting to influence the enterohepatic circulation of bile acids in cystic fibrosis by feeding taurine ${ }^{30}$ in conjunction with method changes to determine soluble bile acid concentrations. Where possible, we are perfusing terminal ileal segments in patients with ileostomies to determine the uptake of taurine and glycine conjugated bile acids in vivo. We hope that this approach may enable further progress to be made in unravelling the complexities of fat malabsorption and bile acid circulation in cystic fibrosis.

\section{FASTING SERUM BILE ACIDS}

The incidence of compromised liver function (38\%), as determined by raised fasting serum bile acid concentrations, more closely reflects the incidence of focal biliary cirrhosis found at necropsy $(>25 \%)^{41}$ and by ultrasound $(39 \%),{ }^{42}$ than the incidence appraised clinically $(2 \%)^{43}$ or that determined by conventional tests of liver function. ${ }^{44}$ The blunted bile acid secretion response to cholecystokinin/ secretin in the group with raised bile acids, supports the contention that raised fasting serum bile acids reflect liver dysfunction.

Although the relative proportion of glycine conjugated bile acids is much higher in cystic fibrosis patients with poor pancreatic function, the rise in fasting serum levels is not merely a reflection of this, but is caused also by significantly raised taurine conjugates.

Our studies support the contention that fasting serum bile acid concentrations are a sensitive indicator of liver dysfunction in cystic fibrosis, as evidenced by the early changes preceding conventional function test changes in three of our cystic fibrosis patients. Samuelsson and Strandvik ${ }^{45}$ point out that raised fasting levels cannot differentiate between cirrhosis and fibrosis. It appears that liver damage in cystic fibrosis is somehow related to the severity of pancreatic dysfunction which may merely reflect disease severity. It could, however, be related to the changes in duodenal and circulating bile acids. Yousef $e t a l^{46}$ have shown that sulpholithocholate is highly toxic in rats when conjugated with glycine but not taurine, and Dorvil et al ${ }^{47}$ showed that taurine prevented intrahepatic cholestasis induced by lithocholic acid sulphate in guinea pigs. Bile acid malabsorption in cystic fibrosis exposes large quantities of bile acid to the colonic bacterial flora, and may be expected to result in increased production of lithocholate. Despite the protective sulphation and excretion of this hepatotoxic bile acid, increased levels may circulate in cystic fibrosis, and one may postulate that liver damage is most likely in those patients with poor pancreatic function who, for whatever reason, circulate an increased proportion of glycine conjugated bile acids over an extended time period. Colombo et $\mathrm{l}^{6}$ measured faecal bile acids in cystic fibrosis and found that they correlated with serum transaminases, prompting the suggestion that bile acid malabsorption has a role in the pathophysiology of liver disease in cystic fibrosis. We have now started studies to determine the in vivo uptake of conjugated bile acids from the gut, and to determine the circulating levels of glycolithocholate in cystic fibrosis and control groups by altering the analysis technique. Long term longitudinal studies of fasting serum bile acid concentrations in cystic fibrosis are being carried out to determine if this parameter represents the most sensitive measurement of liver dysfunction. An extended trial of taurine feeding is also underway to determine if this has a protective effect on the development of liver disease in cystic fibrosis.

We wish to thank the ward staff of the Metabolic Unit for their help with the pancreatic function studies, and the departments of Nutrition \& Dietetics and Chemical Pathology for faecal fat, trypsin, and bromosulphophthalein estimations. We also thank Mrs C Lloyd and staff of the Clinical Photography Department for the figures and Mrs $\mathrm{R}$ Drinkwater for typing the manuscript.

\section{References}

1 Gracey M. Cystic Fibrosis. In: Anderson CM, Burke V, eds. Paediatric gastroenterology. Oxford, London: Blackwell Scientific Publications, 1975: 329-59.

2 Kramer R, Rudeberg A, Adorn B, Rossi E. Relative underweight in cystic fibrosis and its prognostic value. Acta Pediatr Scand 1978; 67: 3-7.

3 Gaskin K, Gurwitz D, Durie P, Corey M, Levison H, Forstner G. Improved respiratory prognosis in patients with cystic fibrosis with normal fat absorption. $J$ Pediatr 1982; 100: 857-62.

4 Watkins JB, Tercyak AM, Szczepanik P, Klein PD Bile salt kinetics in cystic fibrosis: influence of pancreatic enzyme replacement. Gastroenterology 1977; 73: $1023-8$.

5 Nassif EG, Younoszai MK, Weinberger MM, Nassif $\mathrm{CM}$. Comparative effects of antacids, enteric coating, and bile salts on the efficacy of oral pancreatic enzyme therapy in cystic fibrosis. J Paediatr 1981; 98: 320-3. 
6 Colombo C, Morselli AM, Rucci P, Maiavacca R, Ronchi M, Giunta A. Fecal bile acid excretion in patients with cystic fibrosis: correlation with clinical and biochemical parameters. In: Lawson D, ed. Cystic fibrosis: horizons. Proceedings of the 9th international cystic fibrosis congress. Brighton, England. Chichester: Wiley, 1984: 305

7 Weber AM, Roy CC, Morin CL, Lasalle R. Malabsorption of bile acids in children with cystic fibrosis. $N$ Engl J Med 1973; 289: 1001-5.

8 Eklund A, Norman A, Strandvik B. Excretion of bile acids in healthy children and children with cystic fibrosis. Scand J Clin Lab Invest 1980; 40: 595-608.

9 Roy CC, Weber AM, Morin CL et al. Abnormal biliary lipid composition in cystic fibrosis. N Engl J Med 1977; 297: 1301-5.

10 Harries JT, Muller DPR, McCollum JPK, Lipson A, Roma E, Norman AP. Intestinal bile salts in cystic fibrosis. Arch Dis Child 1979; 54: 19-24.

11 Goodchild MC, Murphy GM, Howell AM, Nutter SA, Anderson CM. Aspects of bile acid metabolism in cystic fibrosis. Arch Dis Child 1975; 50: 769-78.

12 Ewerth S. Postprandial serum concentration of individual bile acids in man. Influence of ileal resection. Scand J Gastroenterol 1982; 17: 781-4.

13 Douglas JG, Beckett GJ, Nimmo IA, Finlayson NDC, Percy-Robb IW. Clinical value of bile salt tests in anicteric liver disease. Gut 1981; 22: 141-8.

14 Alm R, Carlson J, Eriksson S. Fasting serum bile acids in liver disease. Scand J Gastroenterol 1982; 17: 213-8.

15 Robb TA, Davidson GP. Analysis of individual bile acids and their glycine/taurine conjugates by high performance thin layer chromatography and densitometry. Ann Clin Biochem 1984; 21: 137-40.

16 Gaskin KJ, Durie PR, Corey M, Wei P, Forstner GG. Evidence for a primary defect of pancreatic $\mathrm{HCO}_{3-}$ secretion in cystic fibrosis. Pediatr Res 1982; 16: 554-7.

17 Gibson LE, Cooke RE. A test for concentration of electrolytes in sweat in cystic fibrosis of pancreas utilizing pilocarpine by iontophoresis. Pediatrics 1959; 23: 545-9.

18 Van de Kamer JH, ten Bokkell Juinink H, Weijers HA. A rapid method for the determination of fat in feces. J Biol Chem 1949; 177: 347-55.

19 Oppe TE, Gibbs IE. Sulpho-Bromo-phthalein excretion in premature infants Arch Dis Child 1959; 34: $125-30$

20 Wiggins HS. Simple method for estimating trypsin. Gut 1967; 8: 415-6.

21 Setchell KDR, Worthington J. A rapid method for the quantitative extraction of bile acids and their conjugates from serum using commercially available reversephase octadecysilane bonded silica cartridges. Clin Chim Acta 1982; 125: 135-44.

22 O'Moore RRL, Percy-Robb IW. Analysis of bile.acids and their conjugates in jejunal juice by thin layer chromatography and direct densitometry. Clin Chim Acta 1973 ; 43: 39-47.

23 Jones DL, Hemphill W. Charts and tables of heights, masses, and head circumference of infants and children. $\mathrm{NH}$ and MRC, Australian Department of Health. Canberra: Australian Government Printing Service,
1975.

24 Badley BWD, Murphy GM, Boucher AD. Intraluminal bile-salt deficiency in the pathogenesis of steatorrhoea. Lancet 1969; 2: 400.

25 Simko V, Kelley RE. Plasma bile acids in health and liver disease: response to cholecystokinin-stimulated gall bladder contraction and to exercise. Gastroenterology 1982; 82: 1245.

26 Balistreri WF, Suchy FJ, Heubi JE. Serum bile acid response to a meal stimulus - a sensitive test of ileal function. Pediatr Res 1979; 13: 395.

27 Weber AM, Roy CC, Chartrand L et al. Relationship between bile acid malabsorption and pancreatic insufficiency in cystic fibrosis. Gut 1976; 17: 295-99.

28 Fenster Sheib MD, Werlin SL, Bruns T, Sty JR. Ultrasound evaluation of the hepatobiliary tract in cystic fibrosis. [Abstract] Pediatr Res 1979; 13: 396.

29 Garbutt JT, Heaton KW, Lack L, Tyor MP. Increased ratio of glycine-to-taurine-conjugated bile salts in patients with ileal disorders. Gastroenterology 1969; 56: 711-20.

30 Stephan ZF, Armstrong MJ, Hayes KC. Bile lipid alterations in taurine depleted monkeys. Am J Clin Nutr 1981; 34: 204-10.

31 Milla PJ, Rassam UB, Kilby A, Ersser R, Harries JT. Small intestinal absorption of amino acids and dipeptides in pancreatic insufficiency. In: Sturgess JM, ed. Perspectives in cystic fibrosis. Toronto, Canada: Canadian Cystic Fibrosis Foundation, 1980: 177-80.

32 McLeod GM, Wiggins HS. Bile salts in small intestinal contents after ileal resection and in other malabsorption syndromes. Lancet 1968; 1: 873-6.

33 Dimagno EP, Malagelada JR, Go VLW, Moertel CG. Fate of orally ingested pancreatic enzymes in pancreatic insufficiency. $N$ Engl J Med 1977; 296: 1318-22.

34 Regan PT, Malagelada JR, Dimagno EP, Go VLW. Reduced intraluminal bile acid concentrations and fat maldigestion in pancreatic insufficiency: correction by treatment. Gastroenterology 1979; 77: 285-9.

35 Bruusgaard A, Thaysen EH. Increased ratio of glycine/ taurine conjugated bile acids in the early diagnosis of terminal ileopathy. Acta Med Scand 1970; 188: 547-8.

36 Igimi H, Carey MC. pH-solubility relations of chenodeoxy-cholic and ursodeoxy-cholic acids: physicalchemical basis for dissimilar solution and membrane phenomena. J Lipid Res 1980; 21: 72-90.

37 Naismith DJ, Cashel KN. Taurine in breast milk: a role in fat utilization. [Abstract] Nutr Soc 1979; 38: 105A.

38 Graham DY. Pancreatic enzyme replacement. The effect of antacids or cimetidine. Dig Dis Sci 1982; 27: 485-90.

39 Fondacaro JD, Heubi JE, Kellogg FW. Intestinal bile acid malabsorption in cystic fibrosis: a primary mucosal cell defect. Pediatr Res 1982; 16: 494-8.

40 Boyle BJ, Long WB, Balistreri WF, Widzer SJ, Huang $\mathrm{N}$. Effect of cimetidine and pancreatic enzymes on serum and fecal bile acids and fat absorption in cystic fibrosis. Gastroenterology 1980; 78: 950-3.

41 Oppenheimer EH, Esterley JR. Hepatic changes in young infants with cystic fibrosis: possible relation to focal biliary cirrhosis. J Pediatr 1975; 86: 683.

42 McHugo JM, Day AJ, McKeown CME, Weller PH, 
Shah KJ. Liver disease: preliminary results on correlation of ultrasound, laboratory and clinical findings. In: Lawson D, ed. Cystic fibrosis: horizons. Proceedings of the 9th international cystic fibrosis congress. Brighton. England. Chichester: Wiley, 1984: 308.

43 di Sant'Agnese PA, Blanc WA. A distinctive type of biliary cirrhosis of the liver associated with cystic fibrosis. Pediatrics 1956; 18: 387-408.

44 Davidson GP, Corey M, Hassel FM, Sondheimer JM, Crozier D. Forstner GG. Immunoassay of serum conjugates of cholic acid in cystic fibrosis. J Clin Pathol
1980; 33: 390-4.

45 Samuelsson K, Strandvik B. Serum bile acids in cystic fibrosis - of no value in diagnosis of liver disease. [Abstract] Pediatr Res 1983; 17: 433.

46 Yousef IM, Tuchweber B, Vonk RJ, Masse D, Audet M, Roy CC. Lithocholate cholestasis: sulphated glycolithocholate-induced intrahepatic cholestasis in rats Gastroenterology 1981; 80: 233-41.

47 Dorvil NP, Yousef IM. Tuchweber B. Roy CC. Taurine prevents cholestasis induced by lithocholic acid sulfate in guinea pigs. Am J Clin Nutr 1983; 37: 221-32. 